\title{
Research on Method of Teaching Chinese as a Foreign Language under the Perspective of Chinese Teaching for Overseas Students
}

\author{
Leichao Ji \\ Heihe University \\ Heihe, Heilongjiang, China 164300
}

\author{
Zhichun Zhu \\ Heihe University \\ Heihe, Heilongjiang, China 164300
}

\begin{abstract}
The retrospect of researching methods for teaching Chinese as a foreign language and the outlook of Ren Yuan "teaching method" is the subject drawn great attention from the Chinese teachers for foreigners. After the teaching objects, teaching contents, and teaching objectives are determined, people want to find an effective, time-saving and labor-saving teaching method. From a large perspective, establish a complete and scientific teaching method system is also one of the marks that the discipline of teaching Chinese as a foreign language has been established.
\end{abstract}

Keywords-overseas students; Chinese as a foreign language; teaching methods

\section{INTRODUCTION}

In teaching Chinese as a foreign language, we shall not only teach them what they are learning, but shall explain why. And the ability to explain is an important index to measure a teacher's credibility in the students. Thus, in the courses of learning Chinese as a foreign Chinese, the teaching of grammar is quite necessary. In the process of teaching grammar, teachers can use the grammar skillfully if they have a profound grammar foundation. To sum up, that is to explain the abstract grammar in plain, simple, and regular method to the students, enabling students to understand that Chinese language also has rules and laws to follow.

\section{OBJECTIVE AND FAIR EVALUATION OF HISTORY}

The special research on methods of teaching Chinese as a foreign language started really from the early 1980s. As the basis of research, there shall be a basic evaluation on the teaching condition, teaching guiding ideology and teaching method principle at 1950 s and 1960 s when this discipline is started to be created. In 1979, the trail issue of "Summary of Fifteen year's Chinese teaching" written by Zhong Qin in 1965 was made in "Language Teaching and Linguistic Studies". The teaching method problems are discussed in detail in this article, which can be regarded as a teaching method monograph with typical significance at that time. Afterwards, Ren Yuan, Li Peiyuan, Zhang Yajun, Yang Shiquan, Wu Yongyi, Xu Zailiang etc. published articles in succession, to summarize, review, analyze and evaluate the teaching principle and teaching method of 1950 s and 1960 s, and to propose some

Funded Project: Higher education and teaching reform project in Heilongjiang Province: bottleneck problems in overseas student education in local colleges in Heilongjiang Province and countermeasures; Project No.: JG2013010440. different views on some of Zhong Wenzhong's ideas. A further step was made for understanding of those problems through reviewing and discussing of the facts. The characteristics of teaching Chinese as a foreign language in 1950 s and 1960s can be summarized as below from the perspective of teaching method research: the core of the teaching path is teaching of vocabulary and grammar rule; teaching principle is to minimize the theoretical lectures, with students' practical activities as main body; teaching goal is to train students' abilities of listening, speaking, reading and writing skills; teaching steps are to implement gradually, to strengthen listening and speaking, lay emphasis on state learning, and develop languages simultaneously. As for the teaching of Chinese as a foreign language at early stage, although it is influenced a lot by the linguistic theory playing a dominant role at that time, its difference with domestic Chinese teaching is noted at the beginning, as it places the cultivation of students' Chinese language ability at a prominent position, and a set of feasible methods has been accumulated from its own teaching practice. The valuable experience has laid a good foundation for the development of this discipline in the future.

\section{Make Clear the Meaning of "Teaching Method", AND CLARIFY ITS RESEARCH SCOPE}

There can be different interpretation of "teaching method". Many people interpret it from the narrow sense, thinking it only refers to the specific teaching methods and techniques. However, from a broad sense, as the object of special research, as a term representing a discipline theory, its connotation is much richer. Then, how should we define the research objects and contents of "methods of teaching Chinese as a foreign language"?

In 1984, Lv Bisong pointed out that: "Language teaching method is a branch of science. Its research objects are the theories, principles and methods relating to the whole process and various links of language teaching. And its research purpose is to explore and clarify the objective law running through the whole language teaching process and various links. (1) In 1986, Zhang Yajun proposed the new term of "pedagogy" and advocated using it to "specifically refer to the research of teaching theory, and call the specific teaching ways, methods and techniques as 'teaching method'."(2) In 1989, 
Sheng Yan published an article, thinking that the task of teaching Chinese as a foreign language is to establish a theoretical system of Chinese language teaching, which is "a complete system of thought, a kind of analysis and integrating approach, and a conceptual framework containing different surveys, different phenomenon and different activities. ',(3)In 1990 and 1991, when Lv Bisong discussed the issue once again, he summarized the discipline theories of teaching Chinese as a foreign language into three aspects: basic theory, teaching theory and teaching method. In order to distinguish in the concepts of "teaching method" at different levels, he advocated expressing them respectively using teaching principles, teaching methods and teaching techniques. He said: "The so-called language teaching method, in fact, is a way to unify language rules and language learning rules, a belt to form language teaching system in accordance with language rules and language learning rules, and an application theory formed by integrated application of language rules and language learning rules', (4) He also believed that teaching theory and teaching method are overlapped. In principle, the language teaching theory is the systematic theory part that can be called "language teaching method". It can be seen from the above discussion that "the method of teaching Chinese as a foreign language" actually contains two aspects: from the macroscopic perspective, it is a complete system of teaching theory, and a series of guiding principles dealing with the relationship between teaching and learning; from the microscopic perspective, it is a set of methods and skills to implement these theories and principles, which has made clear the research category of methods of teaching Chinese as a foreign language, and crucial to the research on this regard.

\section{INTRODUCE AND ABSORB FOREIGN TEACHING THEORIES}

In the 1950s and 1960s, due to the limitations of historical and objective conditions, the understanding and research of linguistics and language teaching theory from Western countries and the former Soviet Union in the field of teaching Chinese as a foreign language is insufficient. In the late 1970s, with changes in domestic and international situation, with the restoration and development of the undertaking of teaching Chinese as a foreign language, people have the opportunity to see the progress of language teaching theory research in foreign countries. For decades, in the introduction and absorption of foreign theory, several items that have great influence on this discipline can be listed as below:

\section{A. Introduce Various Foreign Language Teaching Method Schools Systematically}

In the history of second language teaching in foreign countries, there had been a variety of teaching method schools. In order to make it clear, people have carried out a special collection and presentation. During this period, in addition to articles published in journals, the teaching method research team from Beijing Language College has also sorted out the evaluation materials of modern foreign language teaching method schools, involving up to 17 teaching method schools. (5) Through this work, we have generally made clear the research process of our counterparts in other countries and new theory viewpoints in the period that we were separated from the world academic cycle. Thus we are able to connect to the outside world, enabling ourselves to return to the second language teaching more consciously, and make efforts to keep pace with the development of this discipline.

\section{B. Principles to Introduce "Functional Approach"}

"Functional approach" is a school of teaching method formed after people find the defects of teaching method of "structural school". It emphasizes the essence of language as a tool for communication and stresses role of verbal behavior in realizing communicative purpose. Compared with teaching of Chinese as a foreign language in the 1950s and 1960s, the principle of "functional approach" has very strong pertinence. It urges people to rethink property and characteristics of teaching of Chinese as a foreign language, theory and principle of guided teaching and means and methods of teaching. Absorb reasonable essence and combine with practical situation, so changes happen in macro research of instructional theory, organization of class teaching activities, especially in textbook compilation, (6) which push research on teaching method to a new stage.

\section{Emphasize the Function of Cultural Factor in Teaching}

Since the middle of 1980s, "culture" becomes hotspot in research and practice of teaching of Chinese as a foreign language. During this period, articles involving cross-cultural communication, studies on national conditions as well as relations between language teaching and culture make us inspect teaching of Chinese as a foreign language from a new perspective. "Culture" is a concept with extremely rich connotation. Contents of second language teaching contain certain cultural factors all the time. Specifically analyze function of culture in second language teaching and separate components that influence communication. It has important significance on improving teaching contents, compiling and designing situation for speech training and perfecting principle of training system.

\section{New Thinking of People Caused by Language Acquisition Theory}

In "teaching" and "learning", language teaching theory in the past put "teaching" in leading and core position and once put forward the key to language teaching is "what to teach" and "how to teach". Language acquisition theory starts with the process that learners acquire language competence to reveal the law. This new perspective of consideration enlightens people to find the way to success of language teaching. Based on this, some scholars put forward that in activities of second language teaching, it is necessary to transfer the key point from "teaching" to research on "learning". The new research perspective draws attention of scholars in domestic field of psychological linguistics and foreign language teaching. Articles that evaluate relevant foreign theories and discuss research results appear. Similarly, the field of teaching of Chinese as a foreign language also pays attention to this subject and makes progress in research on Chinese inter-language theory and research on Chinese acquisition. In May 1992, three journal editorial offices of 
Chinese Teaching in the World, Language Application and Language Learning and Research jointly organized forum of "research on language learning theory" (7) Participants communicate research situation with each other and exchange opinions and views. Many propositions and arguments put forward on relations between language learning theory and language teaching theory will have profound influence on promotion of research on teaching method of Chinese as a foreign language.

\section{Progress of Research on TeACHING Method IN RECENT YEARS}

In recent years, teaching method of Chinese as a foreign language changes in worldwide. Most Chinese teachers in America become more mature, practical and tolerant in adoption of teaching method. Generally speaking, most teachers think that the starting point in adopting teaching method is to follow principle of teaching method, integrate with various teaching methods and combine with characteristics of their own. The general situation is, "under the premise of following principle of foreign language teaching, combine deductive method with inductive method, integrate mechanical practice, meaningful practice and communicative practice and use translation method, direct method, audio-lingual method and communicative approach. In the past five years, the eclectic method and comprehensive method are implemented in Chinese teaching in America. Well-trained Chinese teachers with rich experience make the optimization arrangement and strive to acquire the best effect on Chinese teaching to reach teaching objectives according to teaching object, teaching environment and characteristics of their own". (Yin Jinghua, 2005) It shows that although in America, teaching method of Chinese as a foreign language is moving toward prosperity on the whole. To sum up, we can know:

- In recent twenty to thirty years, mainstream of teaching method of western language is communicative approach that emphasizes function and fluent expression. In recent years, it tends to pay attention to structure and grammar and stress fluent, standardized and comprehensive expression.

- Most people reach a consensus on paying attention to teaching of language structure. No language teaching method can separate from language structure. It concerns when to deal with, how to deal with and adopt what kind of method to deal with.

- In the trend of second language teaching in the world, on the whole, in second language teaching of Chinese, comprehensive method that focuses on structure is always in the dominant position and continuous improvement. This teaching method conforms to development tendency of second language teaching in the world.

\section{CONCLUSION}

It is undeniable that grammar teaching plays an important role in teaching of Chinese as a second language. In recent years, the cause of teaching Chinese as a foreign language flourishes. Theoretical exploration and teaching practice of grammar teaching have made considerable development. Research on grammar teaching presents good situation. This paper mainly discusses teaching objectives and teaching methods in grammar teaching. We think that the purpose of grammar teaching is to let learners use Chinese correctly and improve Chinese communicative competence. On teaching, pay attention to grasping methods of practicality and comparability. In teaching Chinese grammar for foreigners, it is necessary to adopt proper measures according to their situation, to meet requirements of learners at different levels.

\section{REFERENCES}

[1] Qiao Yuwei, Zhang Wei. Error Analysis and Teaching Strategies of Separable Word in Chinese International Teaching [J], Theatrical Family, 2015(11): 229-229.

[2] Zhu Zhichun, Kong Yanmei. Research on Bottleneck Problems and Countermeasures of Education for Foreign Students in Local Universities of Heilongjiang [J], Intelligence, 2015(36).

[3] Zhu Zhichun. Teaching Methods Drive Learning Methods - Bottleneck Problems and Countermeasures of Education for Foreign Students in Local Universities of Heilongjiang Province [J], Youthful Days, 2013(5).

[4] Kong Yanmei. Discussion on Problems Existing in Cultural Experience of International Students in China and Countermeasures [J], Intelligence, 2015(36).

[5] Chen Feng. Method of Teaching Chinese as a Foreign Language [M], Zhonghua Book Company, 2008.

[6] Zhao Jinming. Review and Recognition of Method of Teaching Chinese as a Foreign Language [J], Chinese Teaching in the World, 2010 (2): 243-254.

[7] Xu Ziliang. Practical Method of Teaching Chinese as a Foreign Language [M], Peking University Press, 2005. 